\title{
Effects of in vitro addition of infectious pancreatic necrosis virus (IPNV) on rainbow trout Oncorhynchus mykiss leucocyte responses
}

B. Novoa ${ }^{a,}$, A. Figueras ${ }^{b}$, C.J. Secombes ${ }^{\text {a }}$

a : Department of Zoology. University of Aberdeen, Aberdeen, AB9 2TN UK

${ }^{\mathrm{b}}$ : Instituto de Investigaciones Marinas, CSIC. Eduardo Cabello, 6. 36208 Vigo Spain

* Corresponding author at: Instituto de lnvestigaciones Marinas, Vigo, Spain. Tel: 3486-231930; fax: 3486-292762; e-mail: patol@iim.csic.es

\begin{abstract}
Infectious pancreatic necrosis virus (IPNV) did not replicate in rainbow trout macrophages cultured in vitro, but a limited increase in viral titer was observed when total leucocytes were infected with the virus. Macrophages did not respond directly to IPNV, in that IPNV did not trigger the respiratory burst of these cells, even when the macrophages were previously stimulated. Supernatants were generated from leucocytes and macrophages exposed to the virus, using a variety of incubation periods and viral titers, to investigate whether virus stimulation induced the secretion of any immunomodulatory substances from these cells. No effect on macrophage responses was detected when these supernatants were added to new macrophage monolayers. However, IPNV produced a significant reduction of LPS-induced B cell proliferation, in a dose-dependent manner, indicative of at least one immunosuppressive effect induced by this virus.
\end{abstract}

Keywords: IPNU; Oncorhynchus mykiss; Leucocytes; Macrophages

\section{Introduction}

Infectious pancreatic necrosis virus (IPNV) is the prototype strain of the family Birnaviridae, which includes icosaedric unenveloped viruses with double stranded and bisegmented RNA genome. IPNV is an important pathological agent in salmonid aquaculture causing high mortalities mainly in fry. Moreover, it causes diseases in a variety of fish and shellfish species all around the world (Wolf, 1988). 
In spite of the economical losses produced by this virus, there are few reports on the effect of the virus on the fish immune system. Such basic information is vital to understand the pathogenesis of the disease in order to develop efficient control strategies. Several authors have reported the association between IPNV and fish leucocytes (Yu et al., 1982: Knott and Munro. 1986; Mangunwiryo and Agius, 1988; Novoa et al., 1995b) and it has even been propossed that this association can be used as a diagnostic test for the virus in carrier fish by flow cytometry (Rodriguez et al., 1991; Perez et al., 1994). However, salmonid leucocytes cultured in vitro were not considered as target cells for IPNV by Estepa and Coll (1991) and Yu et al. (1982) did not detect the virus in leucocytes by use of an immunofluorescence assay, leading to the conclusion that these cells do not contribute to the high titers of virus found in the haematopoietic organs.

It is known that fish infected with IPNV produce a humoral immune response. For example, Dorson et al. (1992) detected serum interferon activity in rainbow trout fry inoculated with the Sp strain of IPNV and neutralizing antibodies were present in IPNV infected salmonid (Wolf and Quimby, 1969: Yamamoto, 1975; Reno et al.. 1978; Bootland et al.. 1986) and non salmonid (Wechsler et al., 1986; Gastric et al., 1987; Mangunwiryo and Agius, 1987; Novoa et al., 1995a) fish species. Cellular responses, however, have been less studied. Knott and Munro (1986) reported that leucocytes from carrier Atlantic salmon naturally infected with IPNV had a suppressed response to the T cell mitogen PHA in vitro, whereas Estepa and Coll (1991) concluded that IPNV increased the in vitro response of mitogen-stimulated leucocytes. The macrophage also plays an important role in many viral infections (Gendelman and Morahan, 1992). In some cases, this cell acts directly against the virus or can produce cytokines that affect the response of other cell populations of the immune system. To date nothing is known about whether IPNV modulates fish macrophage activity. Thus, the aim of this study was to examine the interaction between IPNV and cells of the immune system of rainbow trout in vitro trout in vitro to determine whether the virus has differential effects on different leucocyte populations.

2. Materials and methods 
The reference serotype of IPNV Sp (Serotype Al) was used for this study being propagated on the Chinook salmon embryo (CHSE-214) cell line. Cells were cultivated at $18^{\circ} \mathrm{C}$ in Eagle's minimal essential medium (MEM, Gibco) supplemented with $10 \%$ fetal calf serum (FCS, Gibco), containing $100 \mathrm{IU}$ penicillin and $100 \mu \mathrm{g}$ streptomycin per $\mathrm{ml}$. Virus was inoculated on the CHSE-214 cell line grown in MEM with antibiotics and $2 \% \mathrm{FCS}$ at $18^{\circ} \mathrm{C}$. When the cytophatic effect was extensive, the supernatant was harvested and centrifuged to eliminate cell debris. Clarified supernatants, without purification were used for all the experiments. The virus stock was titered in 96 multiwell plates using the CHSE-214 cell line according to Reed and Müench (1938). Viral titers were expressed as tissue culture infectious dose $50 \%(\mathrm{TCID} \mu)$.

\subsection{Isolation of macrophages or total leucocytes}

Rainbow trout Oncorhynchus mykiss macrophages were isolated following the method described by Chung and Secombes (1988). Briefly, head kidneys were removed aseptically from trout weighing 200-300 g, that have been humanly killed by destruction of the brain whilst under anaesthesia. The kidneys were passed through a $100 \mu$ m nylon mesh using Leibovitz medium (L15, Gibco) containing heparin (10 units $\mathrm{ml}^{-1}$ ), penicillin $\left(100 \mathrm{IU} \mathrm{ml}^{-1}\right)$, streptomycin $\left(100 \mu \mathrm{g} \mathrm{ml}^{-1}\right)$ and $2 \% \mathrm{FCS}$. The resulting cell suspension was placed on a $34 / 51 \%$ Percoll density gradient or, in the case of total leucocytes, onto $51 \%$ Percoll and centrifuged at $400 \mathrm{x}$ g for $30 \mathrm{~min}$ at $4^{\circ} \mathrm{C}$. The interface cells were collected and washed twice at $400 \mathrm{x}$ g for $5 \mathrm{~min}$ in L15 with $0.1 \%$ FCS. Aliquots of cells in this medium were dispensed into 96 well plates (100 $\mu 1$ per well) or 24 well plates $(1 \mathrm{ml}$ per well). In the case of macrophages, after $3 \mathrm{~h}$ the non-adherent cells were washed off with L15 medium and the monolayers were maintained in L15 + $5 \% \mathrm{FCS}$ at $18^{\circ} \mathrm{C}$ until use. In the case of total leucocytes, after $3 \mathrm{~h}$, FCS was added to each well to give a final concentration of $5 \%$.

\subsection{Replication of the virus in leucocytes}

Macrophages monolayers in 24 well plates (approximately $10^{6}$ cells per well) were infected at a multiplicity of infection (MOI) ranging from 0.2 to 0.5 and incubated for 1 
$\mathrm{h}$ at $18^{\circ} \mathrm{C}$. The monolayers were washed twice with L15 and then incubated in L15 + $5 \%$ FCS for $1,2,3,5$ and 7 days at $18^{\circ} \mathrm{C}$.

Total leucocytes were isolated as described above, infected in tubes $\left(1.5 \times 10^{8}\right.$ cells in $15 \mathrm{ml}$ of L15) with $100 \mu 1$ of IPNV (MOI: 0.2 to 0.5 ) and incubated for $1 \mathrm{~h}$ at $18^{\circ} \mathrm{C}$. After this time, tubes were centrifuged at $400 \mathrm{x}$ g, washed with L15 and the cell pellet resuspended in $20 \mathrm{ml}$ of L15 + 5\% FCS and incubated in 24 well plates for 7 days at $18^{\circ} \mathrm{C}\left(1 \mathrm{ml}\right.$ per well with $5 \times 10^{6}$ cells $\mathrm{ml}^{-1}$ approximately).

Triplicate cultures (macrophage monolayers or leucocytes) were sampled periodically to determine the virus titers in clarified supernatants.

\subsection{Respiratory burst activity}

Macrophage respiratory burst activity was assayed via the reduction of ferricytochrome C by released superoxide anion $\left(\mathrm{O}_{2}\right)$, following stimulation of the cells with phorbol myristate acetate (PMA, Sigma) (Secombes, 1990). Briefly, macrophage monolayers were washed twice in phenol red-free Hank's balanced salt solution (HBSS, Gibco) and $100 \mu$ of HBSS containing ferricytochrome $\mathrm{C}\left(2 \mathrm{mg} \mathrm{ml}^{-1}>\right.$ and PMA $\left(1 \mu \mathrm{g} \mathrm{ml}^{-1}\right)$ was added to each well. As a control for specificity, $300 \mathrm{IU} \mathrm{ml}^{-1}$ superoxide dismutase (SOD, Sigma) was added to some wells. The optical density (OD) was measured at 550 $\mathrm{nm}$ after $60 \mathrm{~min}$, in a multiscan spectrophotometer. Triplicate wells were used in all the experiments and the mean $+\mathrm{SE}$ was calculated. OD were converted to nmol of $\mathrm{O}_{2}$ produced by multiplying by 15.87 as described by Pick (1986).

\subsection{Stimulation of macrophages}

Different experiments were performed to evaluate the influence of IPNV on the respiratory burst of macrophages:

Macrophage monolayers were incubated with three doses of IPNV (High: $1.4 \times 10^{4}$ TCID $_{50}$; Medium: $1.4 \times 10^{3} \mathrm{TCID}_{50}$ and Low: $1.4 \times 10^{2} \mathrm{TCID}_{50}$ ) for varying times ranging between $1 \mathrm{~h}$ and $48 \mathrm{~h}$ (short time course), and 4 and 6 days (long time course), although in the latter case only the high viral dose was assayed. The respiratory burst of 
the macrophage monolayers was measured by the reduction of ferricytochrome $\mathrm{C}$ (described above).

In another experiment, macrophage monolayers were stimulated before the addition of the virus by incubation with trout leucocyte supernatants containing Macrophage Activating Factor (MAF) activity, recombinant tumor necrosis factor CY (rTNF $\alpha$, British Biotechnology), soluble $\beta$-glucans from Saccaromyces cerevisiae (Biotec Mackzymal) and Escherichia coli lipopolysaccharide (LPS, Sigma).

Rainbow trout MAF-containing supernatants were prepared as described by Graham and Secombes (1988). The generated supernatants were tested for activity on the respiratory burst of macrophages (described above) and frozen at $-80^{\circ} \mathrm{C}$. The working dilution of supernatants with known MAF activity was 1:8 in L15 medium plus 5\% FCS.

MAF containing supematants, $25 \mathrm{IU} \mathrm{ml}^{-1} \mathrm{rTNF} \alpha, 50 \mu \mathrm{g} \mathrm{ml}^{-1} \mathrm{LPS}$ (Sigma) or $1 \mu \mathrm{g} \mathrm{ml}^{-1}$ $\beta$-glucans were added to the macrophage monolayers for $24 \mathrm{~h}$. After this, monolayers were washed twice with L15 medium and incubated with $1.4 \times 10^{4}$ TCID50 IPNV for another $24 \mathrm{~h}$ in L15 + 5\%. Stimulated macrophages without IPNV and nonstimulated macrophages with IPNV were included as controls in this experiment. The respiratory burst of the macrophage monolayers was then measured by the reduction of ferricytochrome $\mathrm{C}$ (described above). Finally, the data were expressed as a percentage of the control OD in the absence of IPNV.

\subsection{Production of macrophage and leucocyte supernatants}

IPNV was used to generate macrophage and leucocyte supernatants to investigate whether infected macrophages or leucocytes released factors that modulated macrophage activity. Macrophages or leucocytes obtained from trout head kidney were infected in 24 well plates with IPNV $\left(1.4 \times 10^{4}\right.$ TCID $\left._{50}\right)$ for different incubation times (1, 2 days in the case of total leucocytes, and 1, 2, 4 and 6 days, in the case of macrophages) at $18^{\circ} \mathrm{C}$. After this, the cells were washed twice with $\mathrm{L} 15$ and cultured for a further $24 \mathrm{~h}$ in the absence of stimuli. The supernatants were collected after centrifugation of the culture medium, inactivated by exposure to UV light for $2 \mathrm{~h}$ at a 
distance of $5 \mathrm{~cm}$ (Ahne, 1982) and stored at $-20^{\circ} \mathrm{C}$ until use. New monolayers of macrophages were set up in 96 well culture plates to test the ability of the supernatants to modulate respiratory burst activity (assayed as above) following $48 \mathrm{~h}$ incubation with the cells.

\subsection{Proliferation assay}

The proliferation responses of rainbow trout blood leucocytes were assayed as described by Marsden et al. (1994). Briefly, blood was extracted from the caudal vein with heparinized Vacuettes (Greiner), diluted five times in L15 medium containing 2\% FCS and $0.1 \%$ heparin and centrifuged on $51 \%$ Percoll $\left(400 \mathrm{x}\right.$ g for $30 \mathrm{~min}$ at $\left.4^{\circ} \mathrm{C}\right)$. The interface cells were collected and washed twice at $400 \mathrm{x}$ g for $5 \mathrm{~min}$ in L15 medium plus $0.1 \%$ FCS. Cells were resuspended to $2.5 \times 10^{6}$ cells ml $^{-1}$ in RPM1 1640 medium (Gibco) containing 10 units $\mathrm{ml}^{-1}$ heparin, penicillin $\left(100 \mathrm{IU} \mathrm{ml}^{-1}\right)$, streptomycin $(100 \mu \mathrm{g}$ $\mathrm{ml}^{-1}$ ), $25 \mathrm{mM} \mathrm{NaHCO}_{3}$ and $1 \times 10^{-5} 2 \mathrm{ME}$. Aliquots of $100 \mu \mathrm{l}$ of this suspension were added to wells of a 96 well plate containing $100 \mu \mathrm{l}$ of RPMI 1640 (supplemented as above) plus $12.5,25$ or $50 \mu \mathrm{g} \mathrm{ml}^{-1}$ LPS or without mitogen (used as controls). In addition, each of these combinations was set up containing three different concentrations of IPNV (high, medium and low doses). After a $3 \mathrm{~h}$ incubation period at $15^{\circ} \mathrm{C}$, FCS was added to wells to achieve an overall concentration of $10 \%$. Cells were incubated for 4 days and pulsed with $0.5 \mu \mathrm{Ci}$ of $\left({ }^{3} \mathrm{H}\right)$-thymidine (Amersham). After a further 16-24 $\mathrm{h}$ incubation at $18^{\circ} \mathrm{C}$, leucocyte DNA was harvested onto glass filtermats, $1 \mathrm{ml}$ Xylofluor scintillant (Packard) was added to dried filter circles in vials and counts per minute $(\mathrm{cpm})$ recorded in a liquid scintillation counter (Packard). Triplicate cultures were averaged for every experiment, and data expressed as a stimulation index by dividing the values from cultures in the presence of mitogens by values of cultures in the absence of mitogens, and multiplying by 100 .

\subsection{Statistics}

Data were analyzed using two-way analysis of variance (ANOVA) and Student's t-test.

\section{Results}




\subsection{Replication of IPNV on leucocytes}

No alteration of the morphology of leucocytes (total leucocytes or macrophages) was detected in the presence of IPNV at any incubation time.

The viral titer increased by about $1 \log$ of $\mathrm{TCID}_{50} \mathrm{ml}^{-1}$ with time in leucocyte cultures from blood and from head kidney (Fig. 1(A) and Fig. 1(B)), indicating that a limited viral replication occurred in vitro. In macrophage monolayers, however, the viral titer decreased with time (Fig. 1(C)), suggesting that no replication was occurring.

\subsection{Direct effect of IPNV on macrophage respiratory burst activity}

The influence of IPNV on macrophage respiratory burst activity was studied using different viral doses and times of incubation. Whether using three viral doses over a short time course ( $1 \mathrm{~h}$ to $48 \mathrm{~h}$ ) or only the high viral dose over a long time course ( 4 and 6 days), no significant variation of the response relative to uninfected control macrophages was found (Fig. 2). However, an increase of the respiratory burst of macrophages incubated with the high viral dose after $24 \mathrm{~h}$ was noted and after 4 and 6 days of incubation with $1.4 \times 10^{4} \mathrm{TCID}_{50} \mathrm{ml}^{-1}$ of IPNV the respiratory burst was reduced by $75 \%-80 \%$ relative to control OD values.

\subsection{Effect of IPNV on the respiratry burst of stimulated macrophages.}

The effect of IPNV on stimulated macrophages was also studied. Uninfected, MAF treated macrophages showed an increased respiratory burst when compared with untreated macrophages. In contrast, treatment with glucans, TNF and LPS did not significantly alter the macrophage response. In all cases, no significant differences were found in the respiratory burst between infected and uninfected cultures (Fig. 3).

3.4. Effect of supernatants from infected leucocytes or macrophages on the macrophage respiratory burst

In order to evaluate whether IPNV could induce secretion of immunomodulatory substances, supernatants from infected leucocytes or macrophage monolayers were 
generated. There was no clear pattern in the response of macrophages incubated with these supernatants. In the case of 1 and 2 day supernatants from infected total leucocytes. no variation of the macrophage response was found in comparison with macrophages incubated with control supernatants obtained from non infected leucocytes (Fig. 4(A)). Macrophage supernatants were collected at 1, 2, 4 and 6 days postinfection. The macrophage response to these supernatants was also unaffected in comparison with macrophages incubated with supernatants from uninfected cultures. Only in the case of supernatants from macrophages that had been infected with IPNV for 6 days, and diluted 1:8, was a significant reduction of the macrophage response found (Fig. 4(B)).

\subsection{Effect of IPNV on the proliferation response of trout leucocytes}

The effect of IPNV on the proliferation response of leucocytes was studied using different doses of LPS and IPNV (Fig. 5). LPS caused an increase in leucocyte proliferation (approximately five times above the untreated control). When the effect of IPNV was analyzed at each dose of LPS, a consistent reduction of proliferation was observed compared with uninfected cultures. This decrease was statistically significant in the cases of 25 and $12.5 \mu \mathrm{g} \mathrm{ml}^{-1}$ of LPS using Student's t-test $(\mathrm{P}<0.05)$. Moreover, by two-way ANOVA both LPS dose $(\mathrm{P}<0.05)$ and IPNV dose $(\mathrm{P}<0.05)$ significantly affected leucocyte proliferation, with higher doses of LPS increasing proliferation whereas higher doses of virus reduced proliferation. In nonstimulated cells (no LPS) no effect of IPNV was detected.

\section{Discussion}

Although IPNV has been reported associated with leucocytes (Swanson and Gillespie, 1982; Yu et al., 1982: Knott and Munro. 1986; Rodriguez et al., 1991), it is not clear if the virus can replicate in these cells and what effects this would have on the immune response of fish. In a single study by Knott and Munro (1986), an immunosuppressive effect of IPNV has been demonstrated. These authors found that leucocytes isolated from carrier Atlantic salmon, infected naturally with IPNV, had a suppressed proliferative response to PHA in vitro. The present results indicate that this effect can also be generated by in vitro IPNV infection of leucocytes, as demonstrated by the dose- 
dependent inhibition of LPS-induced proliferation. IPNV effects on PHA proliferation were not examined in the present study due to low baseline stimulation with this mitogen.

If the in vitro studies correlate with the in vivo situation, this could explain why IPNV infected fish have a limited ability to mount an immune response against secondary pathogens, increasing the susceptibility of the infected fish population to disease. This is more important when considering that one aspect of IPNV epidemiology is the carrier state achieved by epizootic survivors or adult fish.

However, the present results contrast with those of Estepa and Co11 (1991). In their work, the leucocyte count (cultures in clots of fibrine) tended to be stimulated in IPNV infected cultures, compared with controls, with or without mitogens. As they postulated, the specific stimulation of the leucocytes could have been due to a previous exposure to the IPNV in the fish farm.

Macrophages play a significant role in non-specific resistence to virus infection, due in part to the non-permissiveness of these cells for the replication of many viruses. This is considered to be a result of an intrinsic resistence (Gendelman and Morahan, 1992). In the present work, no IPNV replication could be found in isolated macrophages and no influence of IPNV infection on the respiratory burst were detected. In general, macrophages display a variable immune function influenced by their state of maturation, differentiation or activation. For this reason, the influence of IPNV infection of stimulated macrophages was also examined but, again, no significant changes were produced in IPNV infected monolayers. However, a decrease of the macrophage respiratory burst was found after direct incubation with virus for 4 and 6 days. In addition, macrophage responses were significantly reduced when incubated with supernatants from macrophages infected with IPNV for 6 days. Although macrophages do not seem to be a main target for the in vitro infection with IPNV, these findings suggest that macrophage responses could be affected by IPNV, although due to limitations of in vitro culture (macrophage viability, variability, etc) no clear effects were apparent. Further in vivo experiments to study the macrophage-IPNV interaction in experimentally infected fish are currently in progress. This is particularly important 
to determine since the release of cytokines by macrophage can modulate the response of other cells of the immune system in IPNV infected fish.

In conclusion, the small increase of viral titer in total leucocytes suggests that other cell types support IPNV replication. The fact that the initial titer of IPNV is different in blood and kidney leucocytes is striking. For this reason, more studies are being done to clarify the entry and replication of this virus in fish leucocytes. Nevertheless, the impaired responses found in LPS-induced proliferation suggest that fish B cells are potentially infected by IPNV, and that whilst this may not produce a significant virus titre it may have major implications for the type of immune response elicited during infection. Clearly, further studies are needed to determine more precisely the number and nature of leucocytes infected by IPNV.

Acknowledgements

This research was partially supported by The British Council (UK), the Ministerio de Educacion y Ciencia (Spain) and CICYT through Coordinated Action HB 93-131 and Grant AGF93-0679-C02-02. Beatriz Novoa acknowledges the Ministerio de Education y Ciencia (Spain), for the research fellowship in the Department of Zoology, University of Aberdeen. UK.

References

Ahne, W., 1982. Vergleichende untersuchungen über die stabilitat von vier fischpathogenen viren (VHSV. PFR, SVCV, IPNV). Zentralbl. Veterinarmed. (B), 29: 457-476.

Bootland, L.M., Stevenson, R.M.W. and Dobos, P., 1986. Experimental induction of the carrier state in yearling brook trout: a model challenge protocol for IPNV immunization. Vet. Immunol Immunopathol., 12: 365-372.

Gastric, J., Baudin-Laurencin, F., Coustans, M.F. and Auffret, M., 1987. Isolation of infectious pancreatic necrosis virus Ab serotype from epizootic in farmed turbot, Scophthalmus maximus. Aquaculture. 67: 117-126.

Chung, S. and Secombes, C.J., 1988. Analysis of events occurring within teleost macrophages during the respiratory burst. Comp. Biochem. Physiol., 89B: 539-544. 
Dorson, M., De Kinkelin, P. and Torchy, C., 1992. Interferon synthesis in rainbow trout fry following infection with infectious pancreatic necrosis virus. Fish Shellfish Immunol., 2: 311-313.

Estepa, A. and Coil, J.M., 1991. Infection of mitogen-stimulated trout leucocytes with salmonid viruses. J. Fish Dis., 14: 555-562.

Gendelman, H.E. and Morahan, P.S., 1992. Macrophages in viral infections. In: C.E. Lewis and J. O`D. McGee (Editors), The Macrophage. IRL Press, Oxford, pp. 157213.

Graham, S. and Secombes, C.J., 1988. The production of macrophage-activating factor from rainbow trout Salmo gairdneri leucocytes. Immunology, 65: 293-297.

Knott, R.M. and Munro, A.L.S., 1986. The persistence of infectious pancreatic necrosis virus in Atlantic salmon. Vet. Immunol. Immunopathol., 12: 359-364.

Mangunwiryo, H. and Agius, C., 1987. Pathogenicity of infectious pancreatic necrosis virus to tilapia and its immune response. The Fisheries Society of the British Isles, 31 (Suppl. A): 255-256.

Mangunwiryo, H. and Agius, C., 1988. Studies on the carrier state of infectious pancreatic necrosis virus infections in rainbow trout, Salmo gairdneri. R. J. Fish Dis., 11: 125-132.

Marsden, M.J., Cox, D. and Secombes, C.J., 1994. Antigen-induced release of macrophage activating factor from rainbow trout Oncorhynchus mykiss leucocytes. Vet. Immunol. Immunopathol., 42: 199-208.

Novoa, N., Rivas, C., Toranzo, A.E. and Figueras, A. 1995a. Pathogenicity of birnaviruses isolated from turbot (Scophthalmus maximus). Comparison with reference serotypes of IPNV. Aquaculture, 130: 7-14.

Novoa, B., Barja, J.L. and Figueras, A., 1995b. Entry and sequential distribution of aquatic birnaviruses in turbot (Scophthalmus maximus). Aquaculture, 131: 1-9.

Perez, S.I., Rodriguez, S. and Vilas, P., 1994. Flow cytometry in fish virology. Techniques in Fish Immunol., 3: 161-173.

Pick, E., 1986. Microassays for superoxide and hydrogen peroxide production and nitroblue tetrazolium reduction using an enzyme immunoassay microplate reader. Meth. Enzymol., 132: 407-421.

Reed, L.J. and Müench, H., 1938. A simple method of estimating fifty per cent endpoints. Amer. J. Hyg., 27: 493-497. 
Reno, P.W., Dailey. S and Savan, M. 1978. Infectious pancreatic necrosis: experimental induction of a carrier state in trout. J. Fish Res. Board Can. 35: 1451-1456.

Rodriguez, S., Vilas, P., Palacios, M.A. and Perez-Prieto, S., 1991. Detection of infectious pancreatic necrosis in a carrier population of rainbow trout, Oncorliynchus mykiss (Richardson), by flow cytometry. J. Fish Dis., 14: 545-553.

Secombes, C.J., 1990. Isolation of salmonid macrophages and analysis of their killing activity. In: J.K. Stolen, T.C. Fletcher, D.P. Anderson, B.S. Roberson and W.B. van Muiswinkel (Editors), Techniques in Fish Immunology. SOS Publications, N J, pp. $137-154$.

Swanson, R.N. and Gillespie. J.H., 1982. Isolation of Infectious Pancreatic Necrosis Virus from the blood and blood components of experimentally infected trout. Can. J. Fish. Aquat. Sci., 39: 225-228.

Wechsler, S.J., Schultz, C.L., McAllister, P.E., May, E.B. and Hetrick, F.M., 1986. Infectious pancreatic necrosis virus in striped bass Morone saxatilis; experimental infection of fry and fingerlings. Dis. Aquat. Org., 1: 203-208.

Wolf, K. 1988. Fish viruses and fish viral diseases. Cornell University Press, Ithaca, NY.

Wolf, K. and Quimby, M.C. 1969. Infectious pancreatic necrosis: Clinical and immune response of adult trouts to inoculation with live virus. J. Fish Res. Board Car., 26: 2511-2516.

Yamamoto, T., 1975. Frequency of detection and survival of infectious pancreatic necrosis virus in a carrier population of Brook trout (Salvelinus fontinalis) in a lake. J. Fish. Res. Board Can., 32 (4): 568-570.

Yu, K.K.Y., MacDonald, R.D. and Moore, A.R., 1982. Replication of infectious pancreatic necrosis virus in trout leucocytes and detection of the carrier state. J. Fish Dis., 5: 401-410. 
Fig. 1. IPNV titer after infection of (A) blood leucocytes, (B) head kidney leucocytes, or (C) head kidney macrophages. Data are expressed as mean Log $\mathrm{TCID}_{50} \mathrm{ml}^{-1}$ for four fish \pm SE.

Fig. 2. Effect of direct incubation of IPNV for $1-48 \mathrm{~h}$ (short time course experiment) or 4 and 6 days (long time course experiment) on macrophage respiratory burst activity. In the short time course experiment, three viral doses were assayed: high dose $\left(1.4 \times 10^{4}\right.$ $\left.\mathrm{TCID}_{50} \mathrm{ml}^{-1}\right)$; medium dose $\left(1.4 \times 10^{3} \mathrm{TCID}_{50} \mathrm{ml}^{-1}\right)$ and low dose $\left(1.4 \times 10^{2} \mathrm{TCID}_{50} \mathrm{ml}^{-}\right.$ $\left.{ }^{1}\right)$. In the long time course experiment, only the highest dose was used. Data are expressed as the percentages of the respiratory burst activity of control macrophages (mean values $\pm \mathrm{SE}$ from four fish).

Fig. 3. Effect of IPNV on the respiratory burst activity of macrophages pre-stimulated with glucans, MAF, TNF, LPS or unstimulated. Data are expressed as mean mmoles $\mathrm{O}_{2}$ produced for three fish $\pm \mathrm{SE}$.

Fig. 4. Respiratory burst activity of rainbow trout head kidney macrophages incubated for $48 \mathrm{~h}$ with control supernatants and two dilutions $(1: 4,1: 8)$ of leucocyte supernatants (A) or macrophages supernatants (B). The supernatants were prepared by incubating leucocytes or macrophages with IPNV (infected supernatants) or medium (uninfected supernatants) for varying periods of time (1 or 2 days for leucocytes supernatants; 1.2. 4 and 6 days for macrophages supernatants). Data are expressed as a percentage (mean $\pm \mathrm{SE}$ of four fish) of the respiratory burst activity of control macrophages $(* \mathrm{P}<0.05)$.

Fig. 5. Proliferation responses of LPS stimulated cells treated with three doses of IPNV or without IPNV (controls). Data are expressed as a stimulation index [mean count $(\mathrm{cpm})$ of stimulated cells per mean count (cpm) of untreated cells] for three fish \pm S.E. $(* \mathrm{P}<0.05)$. 